\title{
A comparative randomized study of awareness during two anesthetic induction techniques in old aged patients using isolated forearm technique
}

\author{
Tamer Hamed Ibrahim, MD $\bowtie$, Ahmed H. Ayoub, MD $\bowtie$, Ibrahim Mohamed Ibrahim, MD $\bowtie$ \\ Mohamed Abdulmohsen Abdulnaiem Ismaiel, MD $\bowtie$, Raham Hasan Mostafa, MD
}

\author{
Author affiliations: \\ Department of Anesthesia, Intensive Care \& Pain Management, Ain Shams University, Cairo, Egypt. \\ Correspondence: Raham Hasan Mostafa, El-hay El-Sabee, Nasr City, Cairo, Egypt.; Phone: 002/01222530020; \\ E-mail: rahamhasan@yahoo.com
}

\section{Abstract}

Background \& Objective: Awareness under anesthesia is defined as intraoperative consciousness and/or postoperative recall of surgical events. The isolated forearm technique (IFT) is a technique that has the ability to assess consciousness of the external world through a verbal command during general anesthesia. It provides live information about the presence of consciousness.

We compared inhalational induction technique versus intravenous induction technique regarding awareness during laryngoscopy and intubation in elderly patients.

Design: A prospective, randomized trial

Methodology: A total of 50 patients scheduled for elective surgery under general anesthesia; aged 60 to 80 years were recruited. Patients were randomized into either Group A (inhalational induction group) or Group B (total intravenous induction group). Awareness reaction using IFT technique was observed during laryngoscopy and intubation phase to identify awareness incidence. A patient was considered a responder if IFT score $>2$.

Results: At laryngoscopy and intubation phase, $32 \%$ of cases had an awareness reaction in intravenous induction group (Group B): While in the inhalational induction group (Group A), only $8 \%$ of cases had an awareness reaction. Additionally, none of the patients, suffered from postoperative explicit recall as detected by modified Brice questionnaire (MBQ).

Conclusions: On the basis of the results of our study, we conclude that intravenous induction of general anesthesia may subject old aged patients to a higher incidence of awareness when compared to inhalational induction technique.

Trial Registration: NCT05019560

Abbreviations: TIVA - Total intravenous anesthesia; IFT - Isolated forearm technique; MBQ - Modified Brice questionnaire; BIS ${ }^{\mathrm{TM}}$-Bispectral Index ${ }^{\mathrm{TM}} ; \mathrm{ETAC}$ - End-tidal anesthetic concentration; MAC - Minimum alveolar concentration

Key words: Awareness; The modified Brice questionnaire; Elderly patients; Isolated forearm technique; Sevoflurane; TIVA

Citation: Ibrahim TH, Ayoub AH, Ibrahim IM, Ismaiel MAA, Mostafa RH. A comparative randomized study of awareness during two anesthetic induction techniques in old aged patients using isolated forearm technique. Anaesth. pain intensive care 2022;26(1):81-88. DOI: 10.35975/apic.v26i1.1772

Received: November 14, 2021, Reviewed: December 18, 2021, Accepted: December 22, 2021 


\section{Introduction}

Old aged patients are considerably vulnerable and sensitive to the stress of surgery and anesthesia. Standard anesthetic doses can cause more profound clinical effects in the elderly, due to their different pharmacokinetics and pharmacodynamics. ${ }^{1}$ This may subject this age category to the possibility of increased incidence of intraoperative awareness \pm postoperative recall due to reduced anesthetic doses in the interest of safety.

Regaining consciousness during general anesthesia ("awareness") is a frightening experience that often causes patients to feel helpless and panicked even when no pain is experienced. ${ }^{2}$ Additionally, it is unethical to operate on a conscious patient. ${ }^{3}$

Recent studies showed the incidence of intraoperative awareness detected by postoperative recall to be 0.1 $0.2 \%$ in low-risk surgical procedures; however, it can reach $1 \%$ for patients at increased risk. ${ }^{4}$

Isolated forearm technique (IFT) (Appendix 1) is a direct method to detect real-time awareness under general anesthesia; through which the patient either does or does not move his/her isolated forearm after verbal instructions. $^{5}$

This study was conducted to compare the incidence of awareness - during laryngoscopy and intubation phase between two techniques for induction of general anesthesia; inhalation and intravenous techniques (total intravenous anesthesia) in old aged patients. We hypothesize that intravenous induction technique would subject old aged patients to a higher incidence of awareness when compared to inhalational induction technique.

\section{Methodology}

\subsection{Ethics}

This was a prospective randomized parallel-group, nonfunded, single-center study (Ain Shams University Hospital) conducted after institutional ethics committee approval. The institutional research committee's ethical criteria and with the 1964 Helsinki Declaration and its later amendments or comparable ethical standards. The study was approved by the Ethics committee of University hospital (FMASU R 153/ 2021) on 4/9/2021, and was registered at Clinical Trial Registry (ClinicalTrials.gov) Identifier: NCT05019560 in accordance with WHO and ICMJE standards. Written informed consent was obtained from all patients. The trial followed the CONSORT statement.

\subsection{Study population}

The study comprised of 50 American Society of Anesthesiologists- Physical status (ASA-PS) I and II patients, aged 60 to $80 \mathrm{y}$, weighing $70-80 \mathrm{~kg}$, both sexes, with intact hearing, undergoing elective day case surgery were included in the study.

The study exclusion criteria were: history of awareness under anesthesia, contraindication to tourniquet use on arm, language barriers, neuromuscular disorders, suspected difficult intubation and more than one attempts of intubation.

\subsection{Study groups}

The patients were randomly assigned to one of two groups:

Group A: Patients received inhalational induction

Group B: Patients received intravenous induction

\subsection{Patients' recruitment, randomization and control of potential bias}

Randomization was performed using a computergenerated random number table in opaque sealed envelopes with 1:1 allocation ratio by an anesthesiologist not directly involved in the trial or patient care. Patients were subsequently followed up by a researcher who was unaware of the group allocation. Thus, the patient and the outcome assessor were blinded to the group allocation.

\subsection{Anesthesia}

An intravenous (IV) catheter was inserted at the dorsum of the patient's non-dominant hand. Full monitoring was applied. IFT was explained to each patient before induction. A tourniquet was placed around the dominant arm after placing a cotton bandage; to be inflated later on to $200 \mathrm{mmHg}$. The headphones of an MP-3 player were placed over the patient's ears and the following command was presented: "Mr/Mrs "Y", open and close your dominant hand twice. This was repeated at predetermined specific timings (before endotracheal intubation, during laryngoscopy and intubation phase (with the insertion of blade to hypopharynx), one minute after intubation. Relationship between Bispectral Index ${ }^{\mathrm{TM}}$ (BIS ${ }^{\mathrm{TM}}$ ) and IFT was investigated regarding classification of responders and non-responders at laryngoscopy phase.

\section{In group A (Inhalational Group)}

Patients received inhalational induction using sevoflurane $8 \%$, and fentanyl $2 \mu \mathrm{g} / \mathrm{kg} \mathrm{IV}$, according to previous guidelines. At a constant BIS value of 50 or less, the tourniquet cuff was inflated then atracurium 0.5 $\mathrm{mg} / \mathrm{kg}$ was given intravenously. After maximum T1depression, laryngoscopy and intubation were performed.

In group B (TIVA group)Total intravenous anesthesia (TIVA) was used in this group. Propofol 1.5 $\mathrm{mg} / \mathrm{kg}$ and fentanyl $2 \mu \mathrm{g} / \mathrm{kg}$ IV were given. Then, propofol infusion at $6 \mathrm{mg} / \mathrm{kg} / \mathrm{h}$ was started. At a constant 
BIS value of 50 or less, the tourniquet cuff was inflated and then atracurium 0.5 $\mathrm{mg} / \mathrm{kg}$ was given intravenously. Once maximum T1- depression was obtained, laryngoscopy and intubation were done. No inhalational agent was used.

Patients with awareness reaction to intubation (IFT Score > 2) were assigned to the "Responders" group. Patients without awareness reaction (IFT Score $\leq 2$ ) were assigned to the "Non-responders" group. One minute after successful intubation, the data collection was stopped and the isolated forearm cuff was deflated. Surgery was then allowed to commence as usual. Two hours and twenty-four hours after extubation, patients were interviewed regarding any experience of dreaming or recall using modified Brice questionnaire (MBQ) (Appendix 2 and 3). Then the principal investigators classified each patient report according to the definitions described in previous literature (Appendices).

\subsection{Sample size calculation}

Sample size was calculated using PASS program version 15 , setting the type- 1 error $(\alpha)$ at 0.05 and power at $80 \%$. Results from a previous study showed that $40 \%$ of TIVA group cases were aware during intubation. We assumed that, $8 \%$ of inhalational group cases will be aware during intubation. Based on this, a sample sizes of 22 in group A and 22 in group B will be needed. However, we included 25 patients per group to take in account for $10 \%$ drop out rate.

\subsection{Data Management and Analysis}

The statistical analysis was performed using SPSS software package version 17 (Chicago, IL). Kolmogorov-Smirnov's test was used to evaluate normal distribution of continuous data. Normally distributed numerical data are presented as mean $\pm \mathrm{SD}$, and differences between groups are compared using the Student's t-test. Categorical variables are analyzed using the chi square test or fisher exact test and are presented as numbers and percentages. Kappa statistics was used to compute the measure of agreement between IFT and BIS methods, Kappa's over 0.75 is excellent, 0.40 to 0.75 is fair to good, and below 0.40 is poor. $\mathrm{P}<0.05$ is considered statistically significant.

\section{Results}

A total of 50 patients completed the study and were analyzed. There were no differences between the two study groups as regards to age, body mass index, gender, and ASA physical status (Table 1).

As regards IFT response; before intubation, no patient followed the command to squeeze the investigator's hand (all were level zero IFT score). On the other hand, there was a significant difference between the 2 study groups as regard incidence of awareness reaction during laryngoscopy and intubation time point. $32 \%$ of TIVA

\begin{tabular}{|c|c|c|c|c|c|}
\hline Response noted & & $\begin{array}{l}\text { Inhalational } \\
\text { Group }\end{array}$ & TIVA Group & $\mathbf{P}$ & Sig \\
\hline \multirow{2}{*}{$\begin{array}{l}\text { Responders during } \\
\text { laryngoscope and intubation by } \\
\text { IFT }\end{array}$} & Non Responder $=\mathrm{IFT} \leq 2$ & $23(92.0)$ & $17(68.0)$ & \multirow[t]{2}{*}{$0.03^{*}$} & \multirow[t]{2}{*}{$S$} \\
\hline & Responder $=\mathrm{IFT}>2$ & $2(8.0)$ & $8(32.0)$ & & \\
\hline \multirow{2}{*}{$\begin{array}{l}\text { Responders after } 1 \mathrm{~min} \text { from } \\
\text { intubation by IFT }\end{array}$} & Non Responder $=\mathrm{IFT} \leq 2$ & $23(92.0)$ & $21(84.0)$ & \multirow[t]{2}{*}{$0.667^{* *}$} & \multirow[t]{2}{*}{ NS } \\
\hline & Responder $=\mathrm{IFT}>2$ & $2(8.0)$ & $4(16.0)$ & & \\
\hline \multirow{2}{*}{$\begin{array}{l}\text { Responders during } \\
\text { laryngoscopy and intubation by } \\
\text { BIS }\end{array}$} & BIS $40-60$ & $18(72.0)$ & $18(72.0)$ & \multirow[t]{2}{*}{$1.0^{*}$} & \multirow[t]{2}{*}{ NS } \\
\hline & $\mathrm{BIS}>60$ & $7(28.0)$ & $7(28.0)$ & & \\
\hline \multirow{2}{*}{$\begin{array}{l}\text { Responders after } 1 \mathrm{~min} \text { from } \\
\text { intubation by BIS }\end{array}$} & BIS $40-60$ & $24(96.0)$ & $25(100.0)$ & \multirow[t]{2}{*}{$1.0^{\star *}$} & \multirow[t]{2}{*}{ NS } \\
\hline & $\mathrm{BIS}>60$ & $1(4.0)$ & $0(0.0)$ & & \\
\hline
\end{tabular}




\begin{tabular}{|c|c|c|c|c|c|}
\hline \multirow{2}{*}{\multicolumn{2}{|c|}{ Response }} & \multicolumn{2}{|c|}{$\begin{array}{l}\text { Responses during laryngoscopy } \\
\text { time point by IFT }\end{array}$} & \multirow[t]{2}{*}{ Kappa } & \multirow[t]{2}{*}{ Sig } \\
\hline & & Responder & Non Responder & & \\
\hline \multirow{2}{*}{$\begin{array}{l}\text { Response at } \\
\text { laryngoscopy } \\
\text { by BIS }\end{array}$} & $\begin{array}{l}\text { BIS }>60= \\
\text { Responder }\end{array}$ & $5(50.0)$ & $9(22.5)$ & \multirow[t]{2}{*}{0.239} & \multirow[t]{2}{*}{0.118 (NS) } \\
\hline & $\begin{array}{l}\text { BIS } 40-60= \\
\text { Non-responder }\end{array}$ & $5(50.0)$ & $31(77.5)$ & & \\
\hline \multirow[t]{2}{*}{$\begin{array}{l}\text { Response at intubation } \\
\text { by BIS }\end{array}$} & $\begin{array}{l}\text { BIS }>60= \\
\text { Responder }\end{array}$ & $0(0.0)$ & $1(2.3)$ & \multirow[t]{2}{*}{0.036} & \multirow[t]{2}{*}{1.0 (NS) } \\
\hline & $\begin{array}{l}\text { BIS } 40-60= \\
\text { Non-responder }\end{array}$ & $6(100.0)$ & $43(97.7)$ & & \\
\hline
\end{tabular}

\begin{tabular}{|c|c|c|c|c|c|}
\hline \multicolumn{2}{|l|}{ Parameter } & Inhalational Group & TIVA Group & $\mathbf{P}$ & Sig \\
\hline \multicolumn{2}{|l|}{ Duration of surgery } & $51.56(6.31)$ & $50.84(7.51)$ & $0.715 \ddagger$ & NS \\
\hline \multicolumn{2}{|c|}{ Duration of intubation (seconds) } & $10.28(3.12)$ & $10.72(3.22)$ & $0.626 \ddagger$ & NS \\
\hline \multirow[t]{4}{*}{ Type of surgery } & ERCP & $13(52.0)$ & $10(40.0)$ & \multirow[t]{4}{*}{$0.777^{\star \star}$} & \multirow[t]{4}{*}{ NS } \\
\hline & Glaucoma & $2(8.0)$ & $3(12.0)$ & & \\
\hline & Lipoma excision & $4(16.0)$ & $3(12.0)$ & & \\
\hline & Vitrectomy & $6(24.0)$ & $9(36.0)$ & & \\
\hline \multirow[t]{2}{*}{ Mallampati score } & 1 & $16(64.0)$ & $16(64.0)$ & \multirow[t]{2}{*}{$1.0^{*}$} & \multirow[t]{2}{*}{ NS } \\
\hline & II & $9(36.0)$ & $9(36.0)$ & & \\
\hline
\end{tabular}

\begin{tabular}{|l|l|l|l|l|}
\hline Table 5: Comparative hemodynamic parameters in the $\mathbf{2}$ study groups & & \\
\cline { 2 - 5 } & Inhalational Group & TIVA Group & P & Sig \\
\hline MAP Baseline & $89.28(12.18)$ & $90.76(9.90)$ & 0.639 & NS \\
\hline MAP after intubation & $93.28(8.73)$ & $99.40(11.84)$ & $\mathbf{0 . 0 3 8}$ & S \\
\hline HR Baseline value & $94.00(10.83)$ & $88.28(12.81)$ & 0.074 & NS \\
\hline Heart rate after intubation & $98.60(13.53)$ & $95.72(12.63)$ & 0.440 & NS \\
\hline Data presented as Mean $\pm S D,{ }^{*}$ 'Student $t$-test & & & \\
\hline
\end{tabular}

group cases were responders (IFT>2) compared to only $8 \%$ of inhalational group. Additionally, although there was no significant difference between the 2 study groups after 1 minute of intubation; the incidence was still higher in TIVA group than inhalational group (16\% vs. $8 \%)$ (Table 2)

Before intubation, mean BIS value was $\leq 50$ with no difference between groups. Additionally, there was no significant difference between the 2 study groups as regard BIS values whether at laryngoscopy phase or after 1 minute from intubation. (Table 2)

There was a poor agreement between BIS and IFT in classifications of responders and non-responders at laryngoscopy phase $($ kappa $=0.239)$, as $50 \%$ only of responder by IFT were classified as responder by BIS, and $77.5 \%$ of non-responders were classified as nonresponder by BIS. Also, there was a poor agreement between BIS and IFT in classifications of responders and non-responders after 1 minute from intubation (kappa = 
0.0369 ), as $0 \%$ of responders by IFT were classified as responders by BIS, and $97.7 \%$ of non-responders were classified as non-responders by BIS (Table 3 ).

Finally, no patient had postoperative recall, as reported by MBQ, whether within $2 \mathrm{~h}$ or $24 \mathrm{~h}$ postextubation.

There were no differences between the 2 study groups as regards to surgical and clinical data (Table 4). Regarding hemodynamic data, there was no significant differences (Table 5).

\section{Discussion}

In this study, we aimed primarily, to compare inhalational induction technique versus intravenous induction technique (TIVA), in old aged patients, regarding awareness reaction incidence. The techniques and the doses were used according to the previous studies. ${ }^{6-13}$ We chose laryngoscopy and intubation time point, as it is associated with more profound stimulation than surgical incision. ${ }^{14}$ Additionally, induction phase of anesthesia usually accounts for half the cases of awareness. ${ }^{15}$

From the 50 patients that completed the study, the number of IFT responders at laryngoscopy time point was 10 . The majority of cases were in TIVA Group: 8 cases out of 25 cases $(32 \%)$. While in the inhalational group, only $2(8 \%)$ cases were IFT responders. We also found that, during laryngoscopy and intubation phase, the differences between hemodynamic variations as well as BIS values were insignificant between the two groups, which may indicate their limited predictive value. Finally, none of the patients, suffered from postoperative explicit recall as assessed by MBQ. ${ }^{11}$

\subsection{Old age and awareness}

The variability in pharmacodynamics and kinetics is high in old aged population. Usually, smaller doses of anesthetics are needed for clinical effect, and the duration of action of medications is prolonged. Therefore dosing should be carefully titrated by the principle: "start low go slow". ${ }^{16}$ Unfortunately, it might lead to the probability of under dosing with subsequent intraoperative awareness, especially due the unavailability of accurate continuous monitoring. Very few studies, with conflicting results, had investigated the incidence of awareness according to age. ${ }^{12,17,18}$ Only one study had used IFT to detect awareness after intubation. ${ }^{17}$

Supporting our results, Pollard and their colleagues ${ }^{18}$ analyzed around 87 thousands patients undergoing general anesthesia, for postoperative awareness using MBQ. Only six patients reported instances of recall configuring an awareness incidence of $0.0068 \%$, which is very low than that reported in the recent literature. ${ }^{4}$ All confirmed cases of recall in that study were due to light anesthesia. The reported patients were found to be of older age $(55.5 \pm 12.5 \mathrm{y})$. The very low awareness incidence could be attributed to: the method of data collection that might have missed some subtle cases of awareness as it was a retrospective study, the frequency of patient interviews, and the anesthetics given mostly as per balanced anesthesia protocols, that rely heavily on the use of halogenated anesthetic compounds combined with intravenous narcotics. Balanced anesthesia protocols were assumed by some authors to have a very low incidence of awareness. ${ }^{14}$

On the other hand, other researchers, using MBQ, identified a total of 25 awareness cases out of 19000 patients undergoing general anesthesia through a prospective cohort study ( $0.13 \%$ incidence). They stated that age did not influence the incidence of awareness. ${ }^{12}$ Similarly, Sanders and their colleagues through a prospective cohort study on the incidence of connected consciousness after tracheal intubation, reported an incidence of $4.6 \%$ (12 out of 260 patients). Responders were younger than non-responders $(39 \pm 17$ vs. $51 \pm 16$ y). ${ }^{17}$

\subsection{Awareness during laryngoscopy and intubation phase}

Generally, our results agree with the reported incidence range of real-time awareness reaction - as detected by IFT, during laryngoscopy and intubation in previous literature; whether intubation and laryngoscopy were done after rapid sequence induction, giving an incidence of $36 \%$, or using TIVA, reporting variable incidences of $24 \%, 40 \%, 65 \%$ in different studies. ${ }^{13}, 19,20,21$.

Surprisingly, three studies reported an incidence of awareness reaction either: $100 \%,{ }^{22}$ or zero $\% .^{14,23}$

Russel and colleagues, conducted their study on 12 women undergoing gynecological surgeries using TIVA. IFT responses occurred in all the 12 patients at some time during surgery. ${ }^{22}$ Baraka and their colleagues on the other hand, observed a negative IFT response in all of the 13 full term patients that had undergone cesarean section with an induction to delivery time $<10 \mathrm{~min} .{ }^{23}$ Ketamine and succinylcholine were used for rapid sequence induction. They attributed their results that ketamine decreased maternal intraoperative awareness. Finally, Parate and colleagues used inhalational based balanced anesthesia, and reported zero incidence of awareness reaction. ${ }^{14}$ They stated that after intravenous induction, commencing inhalational agent before laryngoscopy could be a potential solution to reduce awareness reaction. Additionally, the genetic and ethnic impact could be another factor.

\subsection{TIVA versus Inhalational technique}

TIVA-based technique carries more risk of awareness than end-tidal anesthetic concentration (ETAC)-based inhalational agent technique. ${ }^{24}$ It could be attributed to 
multiple factors. First; propofol has wider interpatient variability in adequate dose requirement and at present, we still lacks easy and rapid monitoring technique for it. Secondly; propofol dose required to make the patient unresponsive may not be adequate to attain unconsciousness. ${ }^{14}$ On the other hand, the MAC requirement for movement suppression is usually higher than MAC for suppression of consciousness (i.e., MACawake). ${ }^{25}$ Thirdly, use of inhalation agents with low blood solubility (e.g., sevoflurane and desflurane) allows relatively rapid adjustments in anesthetic concentration and corresponding anesthetic depth. ${ }^{26}$

In our study, we found a higher incidence of awareness reaction using IFT in TIVA group during laryngoscopy and intubation phase. Similarly, researchers detected awareness reaction using IFT in all 40 to $100 \%$ of the patients with TIVA. ${ }^{13,22}$ A study used the LMAFastrach $^{\mathrm{TM}}$ insertion technique and remifentanil/propofol anesthesia (titrated to a BIS of 40 to 65 using TIVA) ${ }^{27}$ Number of IFT responders was $7 / 51$ (13.5\%). This low percentage of awareness reaction could be attributed to the fact that the stimulus of laryngoscopy and intubation might be greater than that of LMA-Fastrach ${ }^{\mathrm{TM}}$ intubation.

\subsection{Postoperative recall using $M B Q$}

In our study, using MBQ at 2 and $24 \mathrm{~h}$ postoperatively, no patient had evidence of explicit recall of intraoperative events. This could be explained that the highest IFT response score in our patients was "level 3", and it is known that level 4 or 5 responses, usually are associated with a higher rate of recall. ${ }^{9}$ Our results are in concordant with the findings of many previous studies. ${ }^{14}, 17,19$ Opposed to our data, a large study diagnosed 25 awareness cases out of 19 thousands patients. ${ }^{12}$ The researchers interviewed the patients twice. In their study, approximately one third of the cases of awareness were detected in the second interview. They followed previous literature which demonstrated that approximately $35 \%$ of postoperative recall cases, are usually detected at a delayed postoperative interview. ${ }^{28}$

\section{Limitation}

IFT provides real-time information about the presence of consciousness. But this valuable tool is not without limitations. For one, the patients with connected consciousness may not be able to respond to the command, despite hearing it (for example, due to impaired motivation or anesthetic actions on motor responses). As such, the IFT is a modest estimate of connected consciousness. Moreover, this technique does not allow for the prediction of return of consciousness and prevention of inadequate anesthesia. Finally, with increased duration of cuff inflation (less than $20 \mathrm{~min}$ is suggested), the method becomes less reliable, because anaerobic metabolism impairs neuromuscular function. Finally, rather than conducting the postoperative interview three times as advised, we only did it twice. It is possible to have a delayed recall of events 1-3 weeks after surgery.

\section{Conclusion}

Intravenous induction technique might subject the patients to a higher incidence of awareness when compared to inhalational induction technique, when isolated forearm technique is used to identify it.

\section{Conflicts of Interest}

The authors declare that there were no conflicts of interest.

\section{Authors' contribution}

THI: Study supervision, Drafting

AHA: Conception and design, Drafting

RHM: Drafting, Analysis and interpretation of data

IMI: Acquisition of data. Statistical analysis

MAAI: Conception and design, Statistical analysis

All authors critically revised and reviewed submitted manuscript.

\section{References}

1. Lim BG, Lee IO. Anesthetic management of geriatric patients Korean J Anesthesiol. 2020 Feb;73(1):8-29. [PubMed] DOI: 10.4097/kja.19391

2. Kerssens C, Klein J, Bonke B. Awareness: monitoring versus remembering what happened. Anesthesiology. 2003 Sep;99(3):570-5. [PubMed] DOI: 10.1097/00000542200309000-00011

3. Russell IF. The ability of bispectral index to detect intra-operative wakefulness during isoflurane/air anaesthesia, compared with the isolated forearm technique. Anaesthesia. 2013 Oct;68(10):1010-20. [PubMed] DOI: DOI: 10.1111/anae.12357

4. Chung HS. Awareness and recall during general anesthesia. Korean J Anesthesiol. 2014 May;66(5):339-45. [PubMed] 10.4097/kjae.2014.66.5.339

5. Linassi F, Zanatta P, Tellaroli $P$, Ori C, Carron M. Isolated forearm technique: a meta-analysis of connected consciousness during different general anaesthesia regimens. $\mathrm{Br} \mathrm{J}$ Anaesth. 2018 Jul;121(1):198-209. [PubMed] DOI: 10.1016/j.bja.2018.02.019

6. Hadavi MR, Beihaghi M, Zand F, Sabetian G, Azemati S, Asadpour E. A comparison between thiopental sodium and propofol for induction of anesthesia in elective cesarean section using bispectral index and isolated forearm technique: a randomized, double-blind study. Asian J Anesthesiol. 2019 Sep 1;57(3):93-100. [PubMed] DOI: 10.6859/aja.201909_57(3).0004

7. Hall JE, Ebert TJ, Harmer M. Induction characteristics with $3 \%$ and $8 \%$ sevoflurane in adults: an evaluation of the second stage of anaesthesia and its haemodynamic consequences. 
Anaesthesia. 2000 Jun 15;55(6):545-50. [PubMed] DOI: 10.1046/j.1365-2044.2000.01476.x

8. Ezici M, Bestas A, Erhan OL. As an analgesic ketamine versus fentanyl for total intravenous anesthesia. Saudi J Anaesth. 2013 Jan;7(1):107-8. [PubMed] DOI: 10.4103/1658-354X.109858

9. Pandit JJ, Russell IF, Wang M. Interpretations of responses using the isolated forearm technique in general anesthesia: a debate. Br. J. Anesth. 2015; 115 (suppl 1): i32-i45. [PubMed] DOI: 10.1093/bja/aev106

10. Gaskell AL, Hight DF, Winders J, Tran G, Defresne A, Bonhomme V, et al. Frontal alpha-delta EEG does not preclude volitional response during anaesthesia: prospective cohort study of the isolated forearm technique. $\mathrm{Br} \mathrm{J}$ Anaesth. 2017 Oct 1;119(4):664-673. [PubMed] DOI: 10.1093/bja/aex170

11. Brice $D$, Hetherington $R$, Utting J. A simple study of awareness and dreaming during anesthesia. $\mathrm{Br} \mathrm{J}$ Anaesth. 1970 Jun;42(6):535-42. [PubMed] DOI: 10.1093/bja/42.6.535

12. Sebel PS, Bowdle TA, Ghoneim MM, Rampil IJ, Padilla RE, Gan TJ et al. The incidence of awareness during anesthesia: a multicenter United States study. Anesth Analg. 2004 Sep 1;99(3):833-9. [PubMed] DOl: 10.1213/01.ANE.0000130261.90896.6C

13. Schneider G, Wagner K, Reeker W, Hänel F, Werner C, Kochs E. Bispectral Index (BIS) may not predict awareness reaction to intubation in surgical patients. J Neurosurg Anesthesiol. 2002 Jan;14(1):7-11. [PubMed] DOI: 10.1097/00008506-20020100000002

14. Parate LH, Channaiah SD, Rajappa GC, Singh R, Madhav A, Mahdiyyah M. The study of intraoperative consciousness after tracheal intubation. Anesth Essays Res. Oct-Dec 2018;12(4):843-847. [PubMed] DOI: 10.4103/aer.AER_139_18

15. Russell IF, Sanders RD. Monitoring consciousness under anaesthesia: the 21 st century isolated forearm technique. $\mathrm{Br} \mathrm{J}$ Anaesth. 2016 Jun;116(6):738-40. [PubMed] DOI: 10.1093/bja/aew112

16. Strøm C, Rasmussen LS. Challenges in anaesthesia for elderly. Singapore Dent J. 2014 Dec;35C:23-29. [PubMed] DOI: 10.1016/j.sdj.2014.11.003

17. Sanders RD, Gaskell A, Raz A, Winders J, Stevanovic A, Rossaint $R$, et al. Incidence of connected consciousness after tracheal intubation: a prospective, international, multicenter cohort study of the isolated forearm technique. Anesthesiology. 2017 Feb;126(2):214-22. [PubMed] DOI: 10.1097/ALN.0000000000001479

18. Pollard RJ, Coyle JP, Gilbert RL, Beck JE. Intraoperative awareness in a regional medical system: a review of 3 years'

data. Anesthesiology 2007 Feb;106(2):269-74. [PubMed] DOI: 10.1097/00000542-200702000-00014
19. Zand F, Hadavi SM, Chohedri A, Sabetian P. Survey on the adequacy of depth of anaesthesia with bispectral index and

20. isolated forearm technique in elective Caesarean section under general anaesthesia with sevoflurane. Br J Anaesth. 2014 May 1;112(5):871-8. [PubMed] DOI: 10.1093/bja/aet483

21. Pierre MS, Landsleitner B, Schwilden $\mathrm{H}$, Schuettler J. Awareness during laryngoscopy and intubation: quantitating incidence following induction of balanced anesthesia with etomidate and cisatracurium as detected with the isolated forearm technique. $J$ Clin Anesth. 2000 Mar;12(2):104-8. [PubMed] DOI: 10.1016/s0952-8180(00)00127-6

22. Slavov V, Motamed C, Massou N, Rebufat $Y$, Duvaldestin P. Systolic blood pressure, not BIS, is associated with movement during laryngoscopy and intubation. Can J Anaesth. 2002 Nov 1;49(9):918-21. [PubMed] DOI: 10.1007/BF03016874

23. Russell IF. The narcotrend 'depth of anaesthesia' monitor cannot reliably detect consciousness during general anaesthesia: An investigation using the isolated forearm technique. Br J Anaesth. 2006 Mar;96(3):346-52. [PubMed] DOI: 10.1093/bja/ael017

24. Baraka A, Louis F, Dalleh R. Maternal awareness and neonatal outcome after ketamine induction of anaesthesia for Caesarean section. Can J Anaesth. 1990 Sep;37(6):641-4. [PubMed] DOI: 10.1007/BF03006482

25. Avidan MS, Mashour GA. Prevention of intraoperative awareness with explicit recall: Making sense of the evidence. Anesthesiology. 2013 Feb;118(2):449-56. [PubMed] DOI: 10.1097/ALN.0b013e31827ddd2c

26. Antognini JF, Schwartz K. Exaggerated anesthetic requirements in the preferentially anesthetized brain. Anesthesiology 1993 Dec;79(6):1244-9. [PubMed] DOI: 10.1097/00000542199312000-00015

27. Avidan M, Mashour GA. Awareness with recall following general anesthesia. Up To Date. 2014:1-6. [FreeFullText]

28. Kocaman Akbay B, Demiraran Y, Yalcin Sezen G, Akcali G, Somunkiran $A$. Use of the bispectral index to predict a positive awareness reaction to laryngeal mask airway-Fastrach insertion and intubation. Acta Anaesthesiol Scand. 2007 Nov;51(10):1368-72. [PubMed] DOI: 10.1111/j.13996576.2007.01441.x

29. Sandin RH, Enlund G, Samuelsson P, Lennmarken C. Awareness during anaesthesia: a prospective case study. Lancet. 2000 Feb 26;355(9205):707-11. [PubMed] DOI: 10.1016/S0140-6736(99)11010-9 


\section{Appendix 1: Isolated forearm technique response scale proposed by Pandit ${ }^{9}$}

Level 0: No response or spontaneous movement

Level 1: Random, spontaneous movement, not associated with any stimulus, where the movement does not localize a stimulus; difficult to identify as a meaningful attempt at communication and is possibly even a reflex Level 2: Movement in response to tactile stimulus, including painful stimulus (2a, non-localizing movement; $2 \mathrm{~b}$, movement that localizes the stimulus)

Level 3: Movement response to direct verbal commands (e.g. 'squeeze hand', 'move your fingers')

Level 4: Movement response to choice questions or conversation (e.g. 'Do you want to be more/less asleep?', 'Are you comfortable?')

Level 5: Spontaneous, purposeful movement initiated by the patient that indicates a desire to communicate; associated with Level 3 or 4 responses when the appropriate questions are asked (e.g. waving arm or hand to indicate distress or seek attention to initiate questioning as above)

\section{Appendix 2: Modified Brice questionnaire ${ }^{11}$}

1- What is the last thing you remember before going to sleep?

2- What is the first thing you remember waking up?

3- Do you remember anything between going to sleep and waking up?

4- Did you dream during your procedure?

5- What was the worst thing about your operation?

\section{Appendix 3: Modified Brice questionnaire interpretation and awareness categorization ${ }^{12}$}

1- No awareness: no reported awareness or a vague description, or what had been reported had a high probability of occurring in the immediate pre- or postoperative period; i.e., music, people talking, dressing application

2- Dreaming, possibly associated with awareness

3- Possible awareness: patient unable to recall any event definitely indicative of awareness

4- Awareness: recalled event was confirmed by attending personnel, or the investigators were convinced that the memory was real, but no confirmation could be obtained 